\title{
PERBANDINGAN KECEPATAN PENCACAHAN ANTARA TIMER 0 (8 BIT) DENGAN TIMER 1 (16 BIT) PADA SISTEM MIKROKONTROLER
}

\author{
Arief Hendra Saptadi \\ Program Studi D-III Teknik Telekomunikasi \\ Akademi Teknik Telekomunikasi Sandhy Putra Purwokerto ${ }^{1}$ \\ ariefhs@akatelsp.ac.id
}

\begin{abstract}
ABSTRAK
Penggunaan pewaktu/pencacah dalam sistem mikrokontroler memberikan keuntungan dalam hal tidak membebani sumber daya CPU dan memungkinkan CPU menjalankan tugas lain. Dengan tersedianya pilihan timer/counter 8 bit dan 16 bit, permasalahan yang muncul adalah pemilihan jenis pewaktu/pencacah yang akan digunakan. Dalam eksperimen yang dilakukan, sistem minimum mikrokontroler AVR ATmega8535 telah mencacah suatu bilangan dengan tepat, menggunakan dua pewaktu/pencacah yang berbeda, yaitu Timer/Counter 0 ( 8 bit) dan Timer/Counter 1 (16 bit). Kondisi limpahan yang terjadi dalam siklus pencacahan 8 bit dan 16 bit, masing-masing akan mengaktifkan Register OCR0 dan OCR1AL. Sinyal keluaran dari port B.3 (OC0) dan port D.5 (OC1A) selanjutnya dimasukkan ke osiloskop dan dibandingkan. Dari hasil pengamatan sinyal keluaran telah dibuktikan bahwa kedua jenis pewaktu/pencacah tersebut memiliki kecepatan yang sama. Dengan demikian dapat disimpulkan bahwa pemilihan pewaktu/pencacah akan lebih didasarkan pada fleksibilitas rentang pencacahan, ukuran program maupun waktu eksekusi.
\end{abstract}

Kata kunci : Pewaktu, Pencacah, 8 bit, 16 bit, Mikrokontroler

\begin{abstract}
The application of timer/counter in microcontroller system had provided advantages in a way that it didn't put the burden on CPU resources and enabled CPU to perform other tasks. With the availability of 8-bit and 16-bit timer/counter, the problem laid on the selection of the type of timer/counter being used. From the experiments performed, the minimum system of AVR ATmega8535 microcontroller had precisely counted a number using two different timers/counters, namely, Timer/Counter 0 ( 8 bit) and Timer/Counter 1 (16 bit). The overflow condition achieved on 8-bit and 16-bit counting cycle activated OCRO and OCRIAL registers, respectively. Output signals from port B.3 (OCO) and port D.5 (OC1A) are then fed to oscilloscope and put into comparison. From the observation of output signals, it could be proven that the two different timers/counters had equal counting speed. Hence, it can be concluded that the selection of timers/counters is more likely based on the flexibility of count range, program size and execution time.
\end{abstract}

Keywords: Timers, Counters, 8 bit, 16 bit, Microcontroller

\section{PENDAhUluaN \\ 1. 1. Latar Belakang}

Proses pencacahan (counting) maupun pewaktuan (timing) di dalam mikroprosesor pada dasarnya terkait dengan operasi penghitungan yang bersifat incremental.

Kedua proses tersebut di dalam arsitektur mikrokontroler (dalam contoh ini, AVR ATmega8535) dilakukan oleh bagian Timers/Counters (Gambar 1).

Pada prinsipnya, Timer adalah sebuah pencacah (counter) sederhana. Keunggulan yang dimilikinya adalah bahwa detak masukan dan operasinya terlepas dari eksekusi program $^{[2]}$. Berbeda dengan fungsi delay yang menggunakan sumber daya CPU, Timer adalah piranti peripheral yang berjalan terpisah dari CPU dan hanya membutuhkan CPU saat diperintahkan untuk beroperasi ${ }^{[4]}$.

Proses pencacahan akan berjalan dari nilai awal yang sudah ditentukan, bergerak naik atau turun dengan selisih tertentu untuk mencapai kondisi limpahan (overflow) sekali atau beberapa kali, sebelum mencapai nilai akhir yang dikehendaki.

Proses ini lazimnya berjalan secara berulang-ulang atau berhenti bila kondisi tertentu telah terpenuhi atau bila terdapat interupsi. 


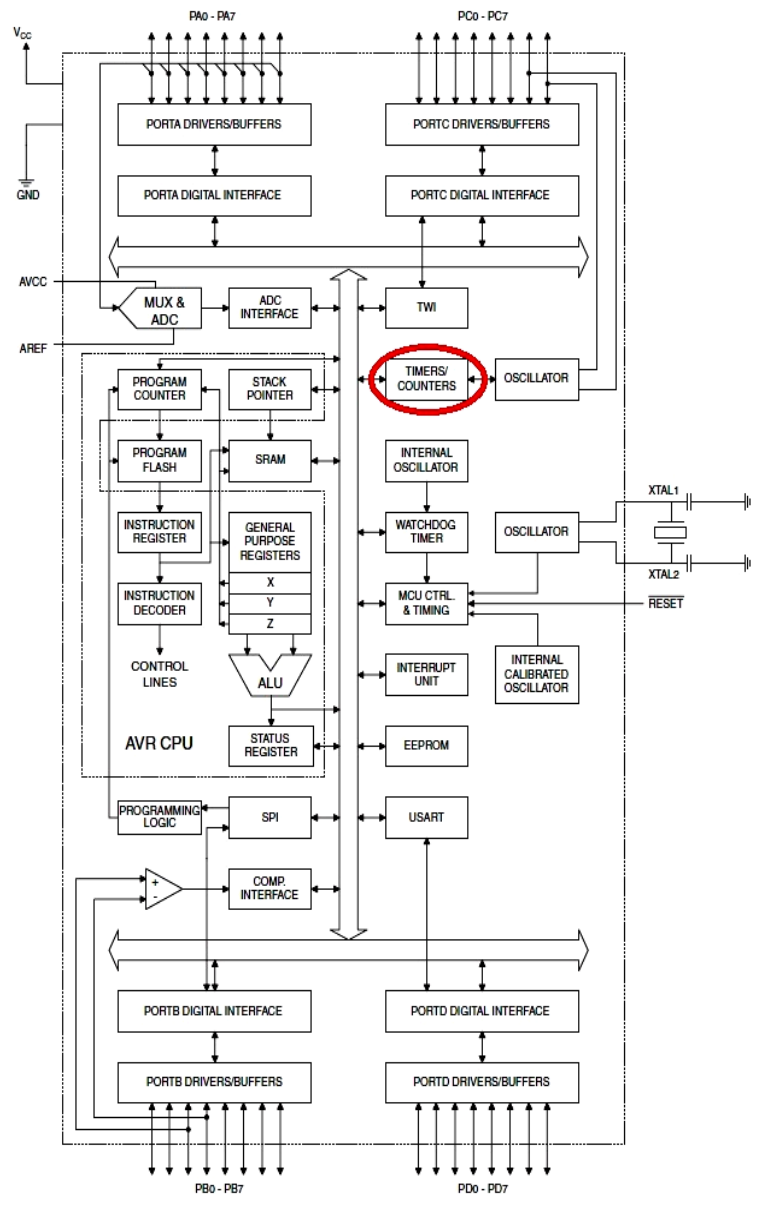

Gambar. 1 Blok Diagram Atmega8535 ${ }^{[1]}$

Timer overflow adalah sebuah kondisi dimana pencacahan sudah mencapai nilai maksimum dan nilai tersebut akan dikembalikan ke nol di siklus detak berikutnya. Nilai maksimum (MaxVal) yang dapat dicacah tergantung dari resolusi (Res) pada timer dan dinyatakan dalam persamaan ${ }^{[2]}$ :

MaxVal $=2^{\text {Res }}-1$

Dengan demikian untuk timer 8 bit, nilai maksimal yang dapat dicacah adalah 255, sementara pada timer 16 bit, adalah sebesar 65535.

Pada mikrokontroler yang memiliki lebih dari satu register timer/counter, terutama dengan jumlah bit yang berlainan (lazimnya, register timer/counter 8 bit dan 16 bit), perlu dilakukan pemilihan mengenai timer/counter mana yang akan digunakan dalam program. Selain itu kecepatan penghitungan antara beberapa jenis timer/counter di dalam mikrokontroler perlu dikaji apakah terdapat perbedaan saat mencacah suatu nilai yang sama, sehingga hal ini dapat dijadikan pertimbangan pemilihan.
Pada penelitian ini dikaji kecepatan penghitungan antara timer 8 bit dan 16 bit saat mencacah sebuah nilai yang sama dalam mikrokontroler ATmega8535 yang memiliki dua buah timer 8 bit dan sebuah timer 16 bit.

\subsection{Tujuan Penulisan}

Dari penjelasan diatas, tujuan yang ingin dicapai dari penelitian ini adalah:

1. Merancang rangkaian sistem minimum untuk pengujian kecepatan timer/counter.

2. Menguji dan membandingkan kecepatan penghitungan antara timer/counter 8 bit dan 16 bit.

\subsection{Batasan Masalah}

Adapun batasan yang diterapkan pada penelitian ini adalah sebagai berikut:

1. Jenis mikrokontroler yang digunakan adalah Atmel AVR ATmega8535.

2. Timer/Counter yang digunakan adalah Timer 0 (8 bit) dan Timer 1 (16 bit).

3. Parameter yang diamati adalah kecepatan penghitungan, berupa periode gelombang keluaran pada pin ke-3 mikrokontroler atau port PB.3 (OC0) dan pin ke-19 atau port PD.5 (OC1A).

4. Penilaian kecepatan penghitungan timer/counter akan didasarkan pada hasil pengamatan pada osiloskop.

\section{KAJIAN PUSTAKA}

Tiga buah Timer/Counter yang terdapat pada mikrokontroler Atmega8535 adalah: Timer/Counter 0 (8 bit), Timer/Counter 1 (16 bit) dan Timer/Counter 2 (8 bit $)^{[1]}$.

\section{A. Timer/Counter 0}

Resolusi dari Timer/Counter 0 ini adalah 8 bit dan register penyimpan datanya TCNT0. Register yang mengatur kinerja Timer/Counter 0 adalah TCCR0 (Timer/Counter Control Register 0) dengan konfigurasi sebagai berikut:

\begin{tabular}{|c|c|c|c|c|c|c|c|c|c|}
\hline \multirow[t]{2}{*}{$B$ Bit } & 7 & 6 & 5 & 4 & 3 & 2 & 1 & 0 & \multirow[b]{2}{*}{ TCCRO } \\
\hline & FOCO & WGIMOO & COllo1 & COMNOO & WGII01 & $\mathrm{CSO} 2$ & $\mathrm{CSS}_{01}$ & $\mathrm{CS} 00$ & \\
\hline ReadWinte & W & RW & RW & RW & $\mathrm{RW}$ & RW & RW & RW & \\
\hline Initial Value & 0 & 0 & 0 & 0 & 0 & 0 & 0 & 0 & \\
\hline
\end{tabular}

Gambar. 2 Register TCRR0 $0^{[1]}$

Kedelapan bit tersebut berhubungan dengan kinerja Timer/Counter 0, masing-masing harus diatur sesuai dengan maksud penggunaannya sebagai berikut:

- Bit 0, 1 dan 2 (CSO0, CSO1, CSO2) 
Ketiga bit tersebut berfungsi untuk memilih sumber clock yang akan digunakan oleh Timer/Counter sebagaimana diperlihatkan dalam Tabel 1.

Tabel 1. Deskripsi Bit Clock Select (CS)

\begin{tabular}{|c|c|c|c|}
\hline CSO2 & CSO1 & c500 & Description \\
\hline 0 & 0 & 0 & No clock source (Timer/counter stopped). \\
\hline 0 & 0 & 1 & clkyo/(No prescaling) \\
\hline 0 & 1 & 0 & $c \mid l k$ IN/8 (From prescaler) \\
\hline 0 & 1 & 1 & clkyol64 (From prescaler) \\
\hline 1 & 0 & 0 & clk, 1256 (From prescaler) \\
\hline 1 & 0 & 1 & clkyd 1024 (From prescaler) \\
\hline 1 & 1 & 0 & External clock source on TO pin. Clock on falling edge. \\
\hline 1 & 1 & 1 & External clock source on TO pin. Clock on rising edge. \\
\hline
\end{tabular}

- Bit 3 dan 6 (WGM01, WGM00)

Merupakan bit pengendali dari kenaikan counter, sumber nilai maksimum counter, clear timer, mode compare match serta dua tipe dari PWM.

Tabel 2. Deskripsi Bit Waveform Generation Mode (WGM)

\begin{tabular}{|c|c|c|l|l|l|l|}
\hline Mode & $\begin{array}{l}\text { WGM01 } \\
\text { (CTC) }\end{array}$ & $\begin{array}{l}\text { WGMO0 } \\
\text { (PWM0) }\end{array}$ & Mode of Operation & TOP & $\begin{array}{l}\text { Update of } \\
\text { OCRO }\end{array}$ & $\begin{array}{l}\text { TOV0 Flag } \\
\text { Set on }\end{array}$ \\
\hline 0 & 0 & 0 & Normal & OxFF & Immediate & MAX \\
\hline 1 & 0 & 1 & PWM, Phase Correct & OxFF & TOP & BOTTOM \\
\hline 2 & 1 & 0 & CTC & OCRO & Immediate & MAX \\
\hline 3 & 1 & 1 & Fast PWM & OxFF & BOTTOM & MAX \\
\hline
\end{tabular}

- Bit 4 dan 5 (COM00, COM01)

Merupakan bit pengendali OC0 (Output Compare Pin). Hal ini berkaitan juga dengan PWM. Bila OC0 dihubungkan ke pin, maka fungsi dari kedua bit tersebut akan tergantung dari pengaturan bit 3 dan 6 (WGM01, WGM00).

Tabel 3, 4 dan 5 masing-masing menunjukkan fungsi dari bit 4 dan 5 bila bit 3 dan 6 diatur ke mode normal atau CTC, Fast PWM dan Phase Correct PWM.

Tabel 3. Mode Non-PWM

\begin{tabular}{|c|c|l|}
\hline COMO1 & COMOO & Description \\
\hline 0 & 0 & Normal port operation, OCO disconnected. \\
\hline 0 & 1 & Toggle OCO on Compare Match \\
\hline 1 & 0 & Clear OCO on Compare Match \\
\hline 1 & 1 & Set OCO on Compare Match \\
\hline
\end{tabular}

Tabel 4. Mode Fast PWM

\begin{tabular}{|c|c|l|}
\hline COMO1 & COMOO & Description \\
\hline 0 & 0 & Normal port operation, OCO disconnected. \\
\hline 0 & 1 & Reserved \\
\hline 1 & 0 & Clear OCO on Compare Match, set OCO at TOP (Non-Inverting). \\
\hline 1 & 1 & Set OCO on Compare Match, clear OCO at TOP (Inverting) \\
\hline
\end{tabular}

Tabel 5. Mode Phase Correct PWM

\begin{tabular}{|c|c|l||}
\hline COM01 & COMO0 & Description \\
\hline 0 & 0 & Normal port operation, OCO disconnected. \\
\hline 0 & 1 & Reserved \\
\hline 1 & 0 & $\begin{array}{l}\text { Clear OCO on Compare Match when up-counting. Set OCO on Compare } \\
\text { Match when down-counting. }\end{array}$ \\
\hline 1 & 1 & $\begin{array}{l}\text { Set OCO on Compare Match when up-counting. Clear OCO on Compare } \\
\text { Match when down-counting. }\end{array}$ \\
\hline
\end{tabular}

- Bit 7 (FOC0)

Bit ini hanya aktif bila bit WGM00 memilih mode non-PWM.

\section{B. Timer/Counter 1}

Resolusi dari Timer/Counter ini adalah 16 bit. Pengaturan Timer/Counter 1 dilakukan $d$ register TCCR1A, TCCR1B, TIMSK dan TIFR. Register penyimpan datanya adalah TCNT1.

\section{B.1. Register TCCR1A (Timer/Counter 1 Control Register A)}

Register ini memiliki susunan bit sebagai berikut:

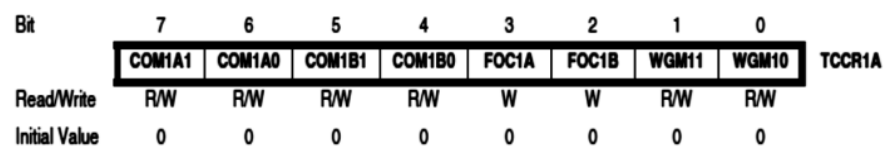

Gambar. 3 Register TCCR1A ${ }^{[1]}$

Fungsi dari masing-masing bit adalah sebagai berikut:

- Bit 0 dan 1 (WGM10, WGM11)

Berfungsi mengendalikan urutan pencacahan dari counter, sumber maksimum (TOP) dari counter dan jenis gelombang yang dibangkitkan. Pengaturannya dikombinasikan dengan register TCCR1B.

- Bit 2 (FOC1B) : Force Output Compare Channel B

- Bit 3 (FOC1A) : Force Output Compare Channel A

- Bit 4 \& 5 (COM1B0 \& COM1B1) : Compare Output Mode Channel B

- Bit 6 \& 7 (COM1A0 \& COM1A1) : Compare Output Mode Channel A 
Tabel 6. Deskripsi Bit Mode Pembangkitan Gelombang

\begin{tabular}{|c|c|c|c|c|l|l|l|l|}
\hline Mode & WGM13 & $\begin{array}{l}\text { WGM12 } \\
\text { (CTC1) }\end{array}$ & $\begin{array}{l}\text { WGM11 } \\
\text { (PWM11) }\end{array}$ & $\begin{array}{l}\text { WGM10 } \\
\text { (PWM10) }\end{array}$ & $\begin{array}{l}\text { Timer/COunter Mode of } \\
\text { Operation }\end{array}$ & TOP & $\begin{array}{l}\text { Update of } \\
\text { OCR1X at }\end{array}$ & $\begin{array}{l}\text { TOV1 Flag } \\
\text { Set on }\end{array}$ \\
\hline 0 & 0 & 0 & 0 & 0 & Normal & OxFFFF & Immediate & MAX \\
\hline 1 & 0 & 0 & 0 & 1 & PWM, Phase Correct, 8-bit & Ox00FF & TOP & BOTTOM \\
\hline 2 & 0 & 0 & 1 & 0 & PWM, Phase Correct, 9-bit & Ox01FF & TOP & BOTTOM \\
\hline 3 & 0 & 0 & 1 & 1 & PWM, Phase Correct, 10-bit & Ox03FF & TOP & BOTTOM \\
\hline 4 & 0 & 1 & 0 & 0 & CTC & OCR1A & Immediate & MAX \\
\hline 5 & 0 & 1 & 0 & 1 & Fast PWM, 8-bit & Ox00FF & BOTTOM & TOP \\
\hline 6 & 0 & 1 & 1 & 0 & Fast PWM, 9-bit & Ox01FF & BOTTOM & TOP \\
\hline 7 & 0 & 1 & 1 & 1 & Fast PWM, 10-bit & Ox03FF & BOTTOM & TOP \\
\hline 8 & 1 & 0 & 0 & 0 & $\begin{array}{l}\text { PWM, Phase and Frequency } \\
\text { COrrect }\end{array}$ & ICR1 & BOTTOM & BOTrOM \\
\hline 9 & 1 & 0 & 0 & 1 & $\begin{array}{l}\text { PWM, Phase and Frequency } \\
\text { COrrect }\end{array}$ & OCR1A & BOTTOM & BOTTOM \\
\hline 10 & 1 & 0 & 1 & 0 & PWM, Phase Correct & ICR1 & TOP & BOTTOM \\
\hline 11 & 1 & 0 & 1 & 1 & PWM, Phase Correct & OCR1A & TOP & BOTTOM \\
\hline 12 & 1 & 1 & 0 & 0 & CTC & ICR1 & Immediate & MAX \\
\hline 13 & 1 & 1 & 0 & 1 & Reserved & - & - & - \\
\hline 14 & 1 & 1 & 1 & 0 & Fast PWM & ICR1 & BOTTOM & TOP \\
\hline 15 & 1 & 1 & 1 & 1 & Fast PWM & OCR1A & BOTTOM & TOP \\
\hline
\end{tabular}

\section{B.2. Register TCCR1B (Timer/Counter 1 Control Register B)}

Register ini juga menentukan kinerja Timer/Counter 1. Konfigurasi bit pada register:

\begin{tabular}{|c|c|c|c|c|c|c|c|c|c|}
\hline \multirow[t]{2}{*}{$R$} & 7 & 6 & 5 & 4 & 3 & 2 & 1 & 0 & \multirow{3}{*}{ TCCRiB } \\
\hline & ICNGI & ICES1 & - & WGMl13 & WGW12 & CS12 & CS1 & CS10 & \\
\hline & RW & RW & $\bar{R}$ & RW & RW & RW & & RW & \\
\hline tal Value & 0 & 0 & 0 & 0 & 0 & 0 & 0 & 0 & \\
\hline
\end{tabular}

Gambar. 4 Register TCCR1B ${ }^{[1]}$

Fungsi dari masing-masing bit adalah sebagai berikut:

- Bit 0,1 dan 2

Berfungsi sebagai Clock Select yaitu pemilih sumber clock bagi timer/counter 1 .

Tabel 7. Deskripsi Bit Clock Select

\begin{tabular}{|c|c|c|c|}
\hline CS12 & CS11 & CS10 & Description \\
\hline 0 & 0 & 0 & No clock source (Timer/Counter stopped). \\
\hline 0 & 0 & 1 & clkyd1 (No prescaling) \\
\hline 0 & 1 & 0 & clkyod8 (From prescaler) \\
\hline 0 & 1 & 1 & clkyo 64 (From prescaler) \\
\hline 1 & 0 & 0 & clky 1256 (From prescaler) \\
\hline 1 & 0 & 1 & clk $k_{10}$ 1024 (From prescaler) \\
\hline 1 & 1 & 0 & External clock source on T1 pin. Clock on falling edge. \\
\hline 1 & 1 & 1 & External clock source on T1 pin. Clock on rising edge. \\
\hline
\end{tabular}

- Bit 3 dan 4 : Waveform Generation Mode $1,2,3$

- Bit 5 : Reserved

- Bit 6 : Input Capture Edge Select

- Bit 7: Input Capture Noise Canceler

\section{B.3. Register TIMSK (Timer/Counter Interrupt Mask Register)}

Register ini memiliki bit-bit kendali interupsi untuk beberapa Timer/Counter. Bit ke-2 hingga ke-5 masuk ke Timer 1.

\begin{tabular}{lcccccc|c|c|c|} 
Bit & 7 & 6 & 5 & 4 & 3 & 2 & 1 & 0 \\
\cline { 2 - 8 } & OCIE2 & TOIE2 & TICIE1 & OCIE1A & OCIE1B & TOIE1 & OCIEO & TOIEO \\
\cline { 2 - 7 } TIMSK \\
ReadWrite & RW & RW & RW & RW & RW & RW & RW & RW \\
Intial Value & 0 & 0 & 0 & 0 & 0 & 0 & 0 & 0
\end{tabular}

Gambar. 5 Register TIMSK ${ }^{[1]}$

Fungsi dari masing-masing bit:

- Bit 0 (TOIE0) : Timer/Counter 0 Overflow Interrupt Enable

Jika TOIE $=1$ dan $1($ pada SREG $)=1$, maka overflow pada timer/Counter 0 menyebabkan interupsi.

- Bit 1 (OCIE0) : Timer/Counter 0 Output Compare Match Interrupt Enable

Jika OCIE0 $=1$ dan $1($ pada SREG $)=1$, maka Output Compare Match Timer/Counter menjadi enable.

- Bit 2 (TOIE1) : Timer/Counter 1 Overflow Interrupt Enable

Jika TOIE $=1$ dan $1($ pada SREG $)=1$, maka overflow pada timer/Counter 1 menyebabkan interupsi.

- Bit 3 (OCIE1B) : Timer/Counter 1 Output Compare B Match Interrupt Enable

Jika OCIE1B = 1 dan 1 (pada SREG) $=$ 1, maka Output Compare B Match Timer/Counter 1 menjadi enable.

- Bit 4 (OCIE1A) : Timer/Counter 1 Output Compare A Match Interrupt Enable

Jika OCIE1A = 1 dan 1 (pada SREG) $=$ 1, maka Output Compare A Match Timer/Counter 1 menjadi enable.

- Bit 5 (TICIE2) : Timer/Counter 1 Input Capture Interrupt Enable

- Bit 6 (TOIE2) : Timer/Counter 2 Overflow Interrupt Enable

Jika TOIE2 $=1$ dan $1($ pada SREG $)=1$, maka overflow pada Timer/Counter 2 menyebabkan interupsi.

- Bit 7 (OCIE2) : Timer/Counter 2 Output Compare Match Interrupt Enable

Jika OCIE2 = 1 dan 1 (pada SREG) $=1$, maka Output Compare Match Timer/Counter 2 menjadi enable. 


\section{B.4. Register TIFR (Timer/Counter Interrupt Flag Register)}

Register ini berhubungan dengan kondisi overflow. Ketika pencacahan Timer/Counter mencapai nilai maksimal (yaitu 255 untuk 8 bit dan 65535 untuk 16 bit), sinyal clock yang datang lagi akan menyebabkan keadaan overflow. Saat terjadi kondisi itulah masingmasing timer memberikan informasi ke Timer/Counter Overflow Flag, untuk mengubah kondisi menjadi set atau "1".

\begin{tabular}{lccccccc|c|c|c|} 
Bit & 7 & 6 & 5 & 4 & 3 & 2 & 1 & 0 \\
\cline { 2 - 9 } & OCF2 & TOV2 & ICF1 & OCF1A & OCF1B & TOV1 & OCFO & TOVO \\
\cline { 2 - 8 } TIFR \\
ReadWrite & RW & RW & RW & RW & RW & RW & RW & RW \\
Intial Value & 0 & 0 & 0 & 0 & 0 & 0 & 0 & 0
\end{tabular}

Gambar. 6 Register TIFR ${ }^{[1]}$

Fungsi dari masing-masing bit:

- Bit 0 (TOV0) : Timer/Counter 0 Overflow Flag

Jika Timer/Counter 0 melimpah (overflow), maka $\mathrm{TOV}=1$, dan dapat dinolkan lagi dengan memberi logika 1.

- Bit 1 (OCF0) : Output Compare Flag 0

Jika nilai Timer/Counter $0=$ nilai OCR0, maka $\mathrm{OCF}=1$.

- Bit 2 (TOV1) : Timer/Counter 1 Overflow Flag

Jika Timer/Counter 1 melimpah (overflow), maka TOV1=1.

- Bit 3 (OCF1B) : Output Compare 1B Match Flag

Jika nilai Timer/Counter1 = nilai OCR1B maka OCF1B = 1 .

- Bit 4 (OCF1A) : Output Compare 1A Match Flag

Jika nilai Timer/Counter $1=$ nilai OCR1A maka OCF1A = 1 .

- Bit 5 (ICF1) : Timer/Counter 1, Input Capture Flag

- Bit 6 (TOV2) : Timer/Counter 2 Overflow Flag

Jika Timer/Counter 2 melimpah (overflow), maka TOV2 $=1$.

- Bit 7 (OCF2) : Output Compare Flag 2

Jika nilai Timer/Counter $2=$ nilai OCR2, maka OCF2 $=1$.

\section{Timer/Counter 2}

Resolusi dari Timer/Counter 2 ini adalah 8 bit. Pengaturannya dilakukan melalui register
TCCR2 (Timer/Counter Control Register 2), TIMSK dan TIFR. Register penyimpan datanya adalah TCNT2. Konfigurasi bit dari register TCCR 2 adalah sebagai berikut:

\begin{tabular}{|c|c|c|c|c|c|c|c|c|}
\hline & 7 & 6 & 5 & 4 & 3 & 2 & 1 & \multirow[t]{2}{*}{0} \\
\hline & FOC2 & WGII20 & COM21 & CON20 & WGI/21 & $\operatorname{cs} 22$ & $\mathrm{CS}_{21}$ & \\
\hline White & W & RW & RW & RW & RW & RW & RW & RW \\
\hline Intial Value & 0 & 0 & 0 & 0 & 0 & 0 & 0 & 0 \\
\hline
\end{tabular}

Gambar. 7 Register TCCR2 ${ }^{[1]}$

Fungsi dari masing-masing bit adalah sebagai berikut:

- Bit 0, 1 dan 2 (CS22, CS21, CS20)

Ketiga bit tersebut berfungsi untuk memilih sumber clock yang akan digunakan oleh Timer/Counter sebagaimana diperlihatkan dalam Tabel 8 .

- Bit 3 dan 6 (WGM21, WGM20)

Merupakan bit pengendali dari kenaikan counter, sumber nilai maksimum counter, clear timer, mode compare match serta dua tipe dari PWM (Tabel 9).

Tabel 8. Deskripsi Bit Clock Select (CS)

\begin{tabular}{|c|c|c|c|}
\hline CS22 & CS21 & $\operatorname{cs} 20$ & Description \\
\hline 0 & 0 & 0 & No clock source (Timer/COunter stopped). \\
\hline 0 & 0 & 1 & $\mathrm{cllk}_{\mathrm{T} 2 \mathrm{~S}}$ (No prescaling) \\
\hline 0 & 1 & 0 & $\mathrm{clk}_{\mathrm{T} 2 \mathrm{~S}} \mathrm{~d}$ (From prescaler) \\
\hline 0 & 1 & 1 & $\mathrm{Clk}_{\mathrm{T} 2 \mathrm{~S}} \mathrm{32}$ (From prescaler) \\
\hline 1 & 0 & 0 & $c \mathrm{ck}_{\mathrm{T} 2 \mathrm{~S}} / 64$ (From prescaler) \\
\hline 1 & 0 & 1 & $\mathrm{clk}_{\mathrm{T} 2 \mathrm{~S}} / 128$ (From proscaler) \\
\hline 1 & 1 & 0 & $\mathrm{clk}_{\mathrm{T} 2 \mathrm{~S}} 256$ (From prescaler) \\
\hline 1 & 1 & 1 & clk $k_{T 2} 1024$ (From prescaler) \\
\hline
\end{tabular}

Tabel 9. Deskripsi Bit Waveform Generation Mode (WGM)

\begin{tabular}{|c|c|c|l|l|l|l|}
\hline Mode & $\begin{array}{l}\text { WGM21 } \\
\text { (CTC2) }\end{array}$ & $\begin{array}{l}\text { WGM20 } \\
\text { (PWM2) }\end{array}$ & $\begin{array}{l}\text { Timer/Counter Mode } \\
\text { of Operation }\end{array}$ & TOP & $\begin{array}{l}\text { Update of } \\
\text { OCR2 }\end{array}$ & $\begin{array}{l}\text { TOV2 Flag } \\
\text { Set on }\end{array}$ \\
\hline 0 & 0 & 0 & Normal & OXFF & Immediate & MAX \\
\hline 1 & 0 & 1 & PWM, Phase Correct & OXFF & TOP & BOTTOM \\
\hline 2 & 1 & 0 & CTC & OCR2 & Immediate & MAX \\
\hline 3 & 1 & 1 & Fast PWM & OXFF & BOTTOM & MAX \\
\hline
\end{tabular}

- Bit 4 dan 5 (COM21, COM20)

Merupakan bit pengendali OC2 (Output Compare Pin). Hal ini berkaitan juga dengan PWM. Bila OC2 dihubungkan ke pin, maka fungsi dari kedua bit tersebut akan tergantung dari pengaturan bit 3 dan 6 (WGM21, WGM20).

Tabel 3, 4 dan 5 masing-masing menunjukkan fungsi dari bit 4 dan 5 bila bit 
3 dan 6 diatur ke mode normal atau CTC, Fast PWM dan Phase Correct PWM.

Tabel 10. Mode Non-PWM

\begin{tabular}{|c|c|l|}
\hline COM21 & COM2O & Description \\
\hline 0 & 0 & Normal port operation, OC2 disconnected. \\
\hline 0 & 1 & Toggle OC2 on Compare Match. \\
\hline 1 & 0 & Clear OC2 on Compare Match. \\
\hline 1 & 1 & Set OC2 on Compare Match. \\
\hline
\end{tabular}

Tabel 11. Mode Fast PWM

\begin{tabular}{|c|c|l|}
\hline COM21 & COM20 & Description \\
\hline 0 & 0 & Normal port operation, OC2 disconnected. \\
\hline 0 & 1 & Reserved \\
\hline 1 & 0 & Clear OC2 on Compare Match, set OC2 at TOP (Non-Inverting). \\
\hline 1 & 1 & Set OC2 on Compare Match, clear OC2 at TOP (Inverting). \\
\hline
\end{tabular}

Tabel 12. Mode Phase Correct PWM

\begin{tabular}{|c|c|l||}
\hline COM21 & COM20 & Description \\
\hline 0 & 0 & Normal port operation, OC2 disconnected. \\
\hline 0 & 1 & Reserved \\
\hline 1 & 0 & $\begin{array}{l}\text { Clear OC2 on Compare Match when up-counting. Set OC2 on Compare } \\
\text { Match when down-counting. }\end{array}$ \\
\hline 1 & 1 & $\begin{array}{l}\text { Set OC2 on Compare Match when up-counting. Clear OC2 on Compare } \\
\text { Match when down-counting. }\end{array}$ \\
\hline
\end{tabular}

- Bit 7 (FOC2)

Bit ini hanya aktif bila bit WGM00 memilih mode non-PWM.

\section{PERANCANGAN PERANGKAT}

Perancangan perangkat yang dilakukan dalam penelitian ini meliputi:

\section{A. Perangkat Keras}

Rangkaian lengkap dari sistem mikrokontroler yang digunakan adalah sebagaimana dalam Gambar 8.

\section{B. Perangkat Lunak}

Pemrograman mikrokontroller dilakukan dengan bahasa $\mathrm{C}$ melalui CodeVision AVR v.2.05.0. Pemilihan compiler tersebut didasarkan atas beberapa pertimbangan berikut $^{[3]}$ :

- Berjalan di Sistem Operasi Windows2000, XP, Vista dan 7, baik untuk versi 32-bit maupun 64-bit

- Memiliki IDE terintegrasi dengan perangkat lunak AVR Chip In-System Programmer

- File COF yang dihasilkan dapat dijalankan menggunakan berbagai simulator
- Dapat digunakan secara bebas (free) sepanjang hasil eksekusi program tidak menghasilkan file dengan kapasitas $>50 \%$ kapasitas PEROM.

Program kemudian diunduh ke mikrokontroller melalui eXtreme Burner AVR v.1.1.

Adapun alur kerja dari program yang dihasilkan adalah sebagaimana diperlihatkan dalam Gambar 9.

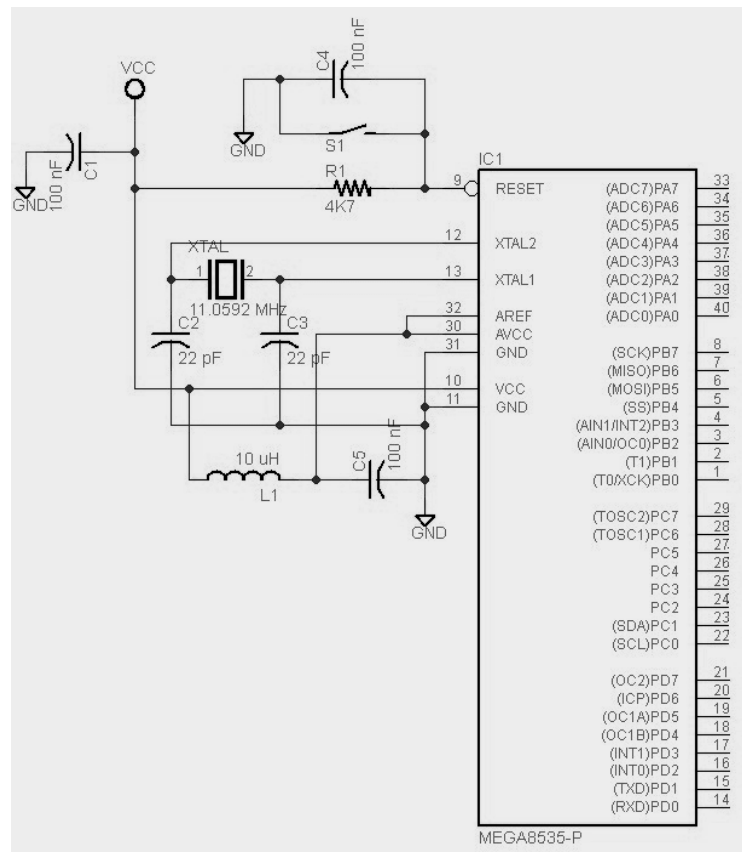

Gambar. 8 Skema Rangkaian

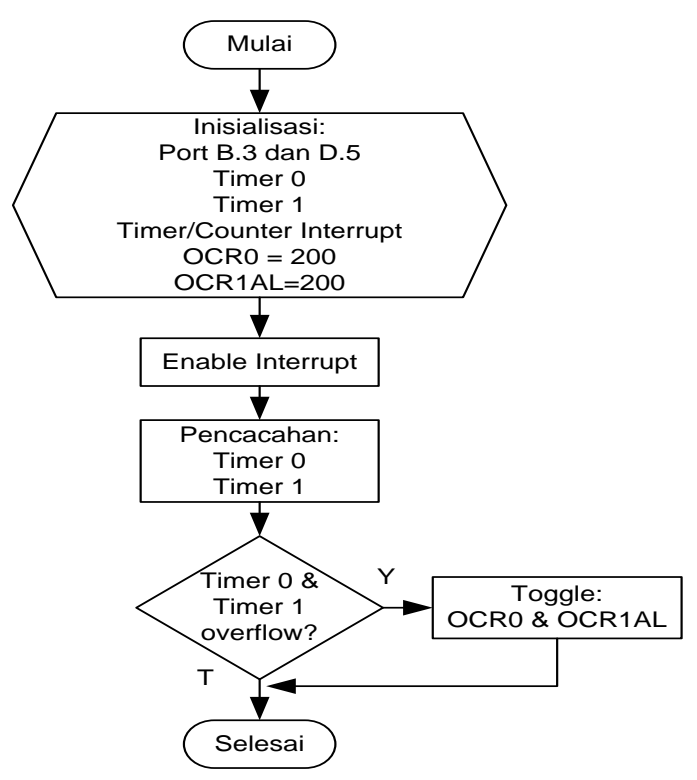

Gambar 9. Diagram Alir Program 
Pada kondisi awal sistem melakukan inisialisasi:

- Port

Yaitu dengan mengatur port B.3 sebagai output untuk OCR0 dan port D.5 sebagai output untuk OCR1AL.

- Timer 0

Sumber clock adalah sistem (osilator kristal). Nilai clock sebesar $250 \mathrm{KHz}$. Mode CTC top $=$ OCR0. Keluaran pada OCR0 dengan kondisi toggle saat compare match. Register OCR0 diatur pada nilai 200 .

- Timer 1

Sumber clock adalah sistem (osilator kristal). Nilai clock sebesar $250 \mathrm{KHz}$. Mode CTC top = OCR1A. Keluaran pada OCR1A dengan kondisi toggle saat compare match. Keluaran pada OCR1B dimatikan. Interupsi Compare A Match diaktifkan, Compare B Match dimatikan. Register OCR1AL diatur pada nilai 200 dan OCR1AH diatur pada nilai nol.

- Interupsi Timer/Counter

Register OCIE1A dan OCIE0 diaktifkan. Setelah itu sistem interupsi secara global diaktifkan melalui instruksi:

\#asm ("sei")

Berikutnya pencacahan pada Timer 0 dan Timer 1 berjalan dengan register TCNT0 dan TCNT1 masing-masing mencacah dari nilai 0 sampai dengan 200.

Saat register TCNT0 dan TCNT1 mengalami overflow, maka register OCR0 (port B.3) dan OCR1AL (port D.5) mengalami toggle, terjadi perubahan sinyal keluaran dari low ke high atau sebaliknya demikian seterusnya.

\section{PENGUKURAN}

Proses pengambilan data pengukuran dilakukan dengan menggunakan osilator digital. Pada langkah pertama dilakukan pengukuran keluaran Timer/Counter 0 pada port B.3 (OC0). Berikutnya dilakukan pengukuran keluaran Timer/Counter 1 pada port D.5 (OC1A). Terakhir, keluaran antara kedua Timer/Counter tersebut saling dibandingkan.

Dari hasil pengukuran tersebut dapat diamati bahwa kecepatan penghitungan antara Timer/Counter 0 dan Timer/Counter 1 adalah sama.
Sinyal keluaran dari OC0:

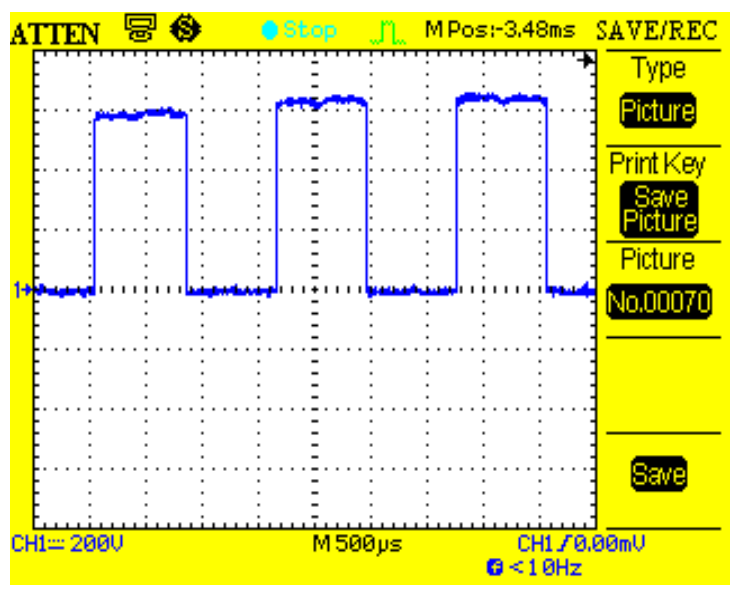

Gambar 10. Keluaran OC0 (Port B.3)

Sinyal keluaran dari OC1A:

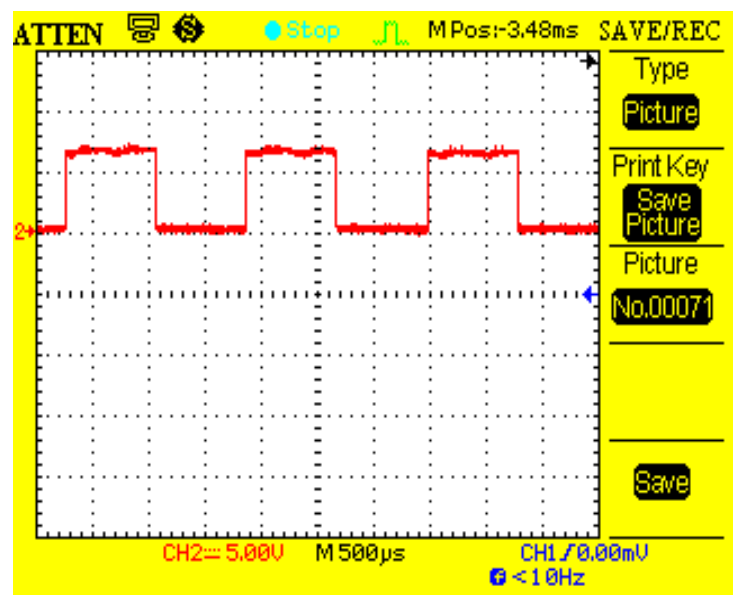

Gambar 11. Keluaran OC1A (Port D.5)

Sinyal keluaran dari OC0 dan OC1A:

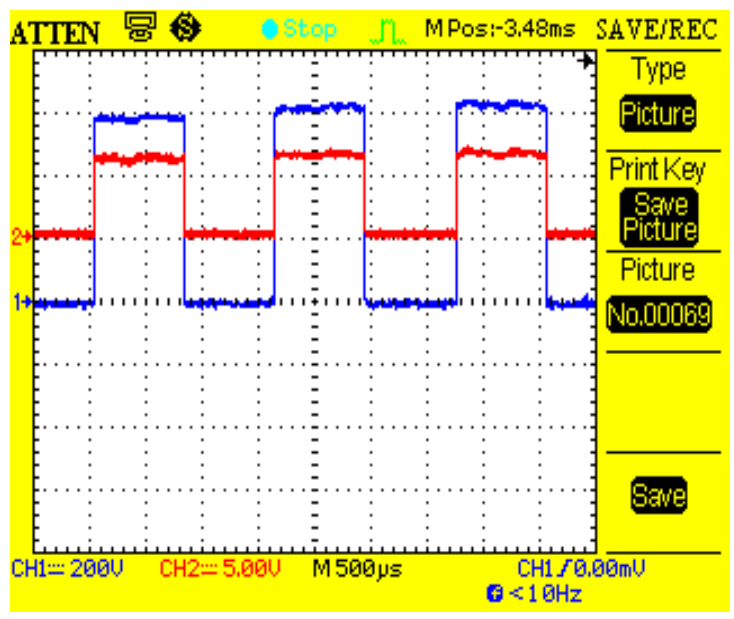

Gambar 12. Keluaran OC0 (Port B.3) dan OC1A (Port D.5)

\section{KESIMPULAN}

Berdasarkan hasil pengukuran tersebut dapat disimpulkan bahwa pencacahan dari nol 
hingga 200 yang dilakukan oleh Timer 0 (8 bit) maupun Timer 1 (16 bit) memiliki periode waktu yang sama. Dengan demikian kecepatan pencacahan dari keduanya adalah sama.

Penggunaan timer 16 bit dengan rentang pencacahan yang lebih lebar daripada timer 8 bit memberikan lebih banyak keleluasaan. Namun untuk banyak aplikasi, penggunaan timer 8 bit sudah lebih dari cukup. Penggunaan timer dengan resolusi yang lebih tinggi memberikan ukuran program yang lebih besar dan membutuhkan waktu eksekusi yang lebih lama $^{[2]}$.

\section{Daftar Pustaka}

[1] ATMEL. 2006. 8-bit AVR Microcontroller with $8 K$ Bytes InSystem Programmable Flash (ATmega8535 \& ATmega8535L), ATMEL.

[2] ATMEL. 2002. AVR130: Setup and Use the AVR Timers. ATMEL.

[3] HP Infotech. 2011. CodeVisionAVR Version 2.05.4 User Manual, Revision 30/09. HP Infotech.

[4] J. Pardue, C. 2005. Programming for Microcontrollers, Featuring ATMEL's AVR Butterfly and the Free WinAVR Compiler. Knoxville, TN, USA: Smiley Micros. 